\title{
Monokristal-monokristal eraldaketak polioxometalatoetan oinarritutako sistemetan: termikoki aktibatutako zenbait adibide
}

(Single-crystal-to-single-crystal transformations in polyoxometalatebased systems: some temperature-triggered examples)

\author{
Leticia Fernández-Navarro' ${ }^{1}$ Estibaliz Ruiz-Bilbao ${ }^{1}$, Beñat Artetxe $^{1 *}$, \\ Leire San Felices ${ }^{2}$, Amaia Iturrospe ${ }^{3}$, Santiago Reinoso ${ }^{4}$ \\ ${ }^{1}$ Kimika Ez-organikoa Saila \\ ${ }^{2}$ Ikerketarako Zerbitzu Orokorrak (SGIker). Zientzia eta Teknologia Fakultatea. \\ Euskal Herriko Unibertsitatea, UPV/EHU \\ ${ }^{3}$ Materialen Fisika Zentroa, CSIC-UPV/EHU \\ ${ }^{4}$ Institute for Advanced Materials, InaMat. Nafarroako Unibertsitate Publikoa
}

\begin{abstract}
LABURPENA: Kanpo-estimuluen bitartez aktibatutako fase-trantsizioak, eta haien artean kristal bakun izaera mantentzen duten kasuak, hots monokristal-monokristal (MKMK) eraldaketak, interes handikoak dira; izan ere, gai dira i) ezaugarri berriak dituzten produktuak emateko eta ii) materialaren propietateetan gertatzen diren aldaketak, egitura kristalinoak jasaten dituenekin erlazionatzeko. Polioxometalatoen (POMen) kasuan bezala, egiturei zurruntasuna ematen dieten oinarrizko unitateak erabiltzea bide egokia da prozesuan zehar gerta litekeen kristalinitatearen galera saihesteko. Gaur egun POMetan oinarritutako sistemetan aurki daitezkeen MKMK eraldaketa urrien artean, aipatzekoak dira termikoki aktibatutako adibideak. Lan honetan azken hauek laburbilduko dira eta bereziki gure ikerketa taldean prestatutako konposatuak eta haien erabilerak (katalisia eta gasen xurgapen selektiboa) goraipatuko ditugu.
\end{abstract}

HITZ GAKOAK: monokristal-monokristal eraldaketak, polioxometalatoak, termikoki aktibatutako fasetrantsizioak.

ABSTRACT: Phase transitions induced by external stimuli in which crystallinity is retained, so-called single-crystal-to-single-crystal transformations (SCSC), are being widely studied because they allow for $i$ ) obtaining products with novel characteristics and ii) correlating structural changes with how a given property of the material is modified. The use of building blocks that provide robustness to the system such as polyoxometalates (POM) are a suitable option to avoid the loss of crystallinity throughout the process. Among the scarce SCSC transformations reported to date for POM-based systems, it is worth highlighting the temperature-triggered examples. This work reviews the later cases with strong focus on the compounds obtained in our research group and their applications (catalysis and selective gas sorption).

KEYWORDS: single-crystal-to-single-crystal transformations, polyoxometalates, thermally-triggered phase transitions.

\footnotetext{
* Harremanetan jartzeko / Corresponding author: Beñat Artetxe, Kimika Ez-organikoa Saila. Zientzia eta Teknologia Fakultatea. Euskal Herriko Unibertsitatea (UPV/EHU), Sarriena Auzoa, zg (48940 Leioa-Bizkaia). - benat.artetxe@ehu.eus https://orcid.org/0000-0002-7373-4596.

Nola aipatu / How to cite: Fernández-Navarro, Leticia; Ruiz-Bilbao, Estibaliz; Artetxe, Beñat; San Felices, Leire; Iturrospe, Amaia; Reinoso, Santiago (2019). «Monokristal-monokristal eraldaketak polioxometalatoetan oinarritutako sistemetan: termikoki aktibatutako zenbait adibidew; Ekaia, 36, 2019, 239-254. (https://doi.org/10.1387/ekaia.20759).

Jasoa: 15 apirila, 2019; Onartua: 3 uztaila, 2019.

ISSN 0214-9001 - elSSN 2444-3255 / ㄷ 2019 UPV/EHU

(c) (1) (2) () Obra hau Creative Commons Atribución 4.0 Internacional-en

BY NC SA lizentziapean dago
} 
Leticia Fernández-Navarro, Estibaliz Ruiz-Bilbao, Beñat Artetxe, Leire San Felices, Amaia Iturrospe, Santiago Reinoso

\section{SARRERA}

Kanpo-estimulu baten eraginez aktibatu eta egoera solidoan gertatzen diren fase-trantsizioak interes handikoak izan daitezke, ohiko metodoen bidez lor ezin daitezkeen konposizio edo egiturak dituzten materialak prestatzeko bidea baitira. Zehazki, trantsizioek konposatuen propietate ezberdinetan (adibidez, porositatean, magnetismoan, lumineszentzian) eragiten dituzten aldaketek haien erabilera zenbait norabidetara bidera dezakete, hala nola, estimulu jakin baten erregistroan oinarritzen den sentsore edo interruptore molekularren aurkikuntzara, edota beste goi-mailako hainbat aplikaziotara (gasen bilketa edo banaketa selektiboa, katalisia...) [1]

Egoera solidoan gertatzen diren eraldaketen artean, aipatzekoak dira ordena, hots kristalinitatea eta kristal-bakun (monokristal) izaera mantentzen dutenak. Hauek «monokristal-monokristal eraldaketak» (MKMK, ingelesez single-crystal-to-single-crystal, SCSC) izena hartzen dute. Azken urteotan, fase-trantsizio hauen inguruko interesa azkar areagotu da; izan ere, kanpo estimulu jakin baten aurrean (presio edo tenperatura aldaketa, argia...) gertatzen diren egitura aldaketei buruzko informazioa jasotzeko aukera ematen dute. Eraldaketa horiek atomo edo molekulen posizioetan gertatu diren mugimenduak aztertu eta, kasurik onenean, hauek materialaren propietateren baten eragindako aldaketekin erlazionatzeko baliagarri dira [2,3]. Oro har, egituraren aldetik gerta daitezkeen eraldaketen artean, hiru trantsizio mota bereiz ditzakegu: polimorfismoak, eraldaketa dinamikoak eta eraldaketa irmoak. Polimorfismoa gorputz solidoek beren izaera eta osakera kimikoa aldatu gabe egitura kristalinoa aldatzeko duten gaitasunean datza, normalean simetria-aldaketa baten ondorio dena. Beste biei dagokienez, lehen taldean lotura kimiko kobalenteak apurtu edo eratzen diren bitartean, bigarrenean jatorrizko egitura kristalinoa mantentzen da, eta gertatzen diren aldaketak txikiak izan ohi dira (adibidez, disolbatzaile molekulen galera edo sarrera, atomoren baten oxidazio-egoeraren aldaketa).

80ko hamarkadan erregistratutako lehen MKMK eraldaketak konposatu organikoetan aztertu ziren arren [4], gaur egun, mota honetako trantsizioak dituzten konposatu asko estekatzaile organiko eta metalen konbinazioz eratutako sare porotsuen artean (MOFen artean) aurki ditzakegu [5, 6]. MOFen (Metal-Organic Framework) inguruko berrikuspen sakona aldizkari honetan bertan argitaratutako lan batean aurkitu daiteke [7]. Praktikan, MKMK fase-trantsizioak jasan ditzaketen MOFak aplikazio eremu desberdinetan erabil daitezke. Adibide gisa, talde aromatiko anitz aurkezten dituzten estekatzaileetan oinarritutako koordinazio polimeroa, $\left\{\left[\mathrm{Cd}_{2}(1,3 \text {-bpeb })_{2}(4-\mathrm{FBA})_{4}\right] \cdot \mathrm{H}_{2} \mathrm{O}\right\}_{\mathrm{n}}(1,3$-bpeb $=1,3$-bis[2-(4-piridil)etenil]-bentzenoa eta 4-FBA = 4-fluorobentzoatoa), nabarmendu genezake. Konposatu honek, argi ultramoreaz irradiatuz gero, bere propietate 
fluoreszenteen aldaketa dakarren MKMK trantsizioa jasaten du eta, horren ondorioz, sentsore optiko bezala erabil daiteke [8]. Bestalde, kimikoki aktibatutako trantsizioen artean, $\mathrm{Cu}^{\mathrm{II}}$-an oinarritutako bi konposatu aipa daitezke: lehenak, $\left[\mathrm{K}(15 \text {-zikloeter-5 })_{2}\right]\left[\mathrm{CuCl}_{3}\right]$ konposatuak, azido klorhidrikoa eta ura era itzulgarrian xurgatzeko ahalmenaren bidez, metalaren koordinazio zenbakian, propietate magnetikoetan eta, 1 . irudian erakusten den bezala, bere kolorean aldaketak eragiten dituzten MKMK transformazioak aurkezten ditu [9]. Bigarren adibidean, $\left[\mathrm{Cu}_{3}(\mathrm{TP})_{4}\left(\mathrm{~N}_{3}\right)_{2}(\mathrm{DMF})_{2}\right]$ $(\mathrm{TP}=4$-tetraazolpiridina eta $\mathrm{DMF}=$ dimetilformamida $)$ koordinazio-sareak disolbatzaile aldaketak eragindako zortzi MKMK fase-trantsizio ditu, non tarteko konposatuetako bat gai den $\mathrm{CO}_{2}$ gasa selektiboki xurgatzeko $\mathrm{N}_{2}$-aren aurrean [10].

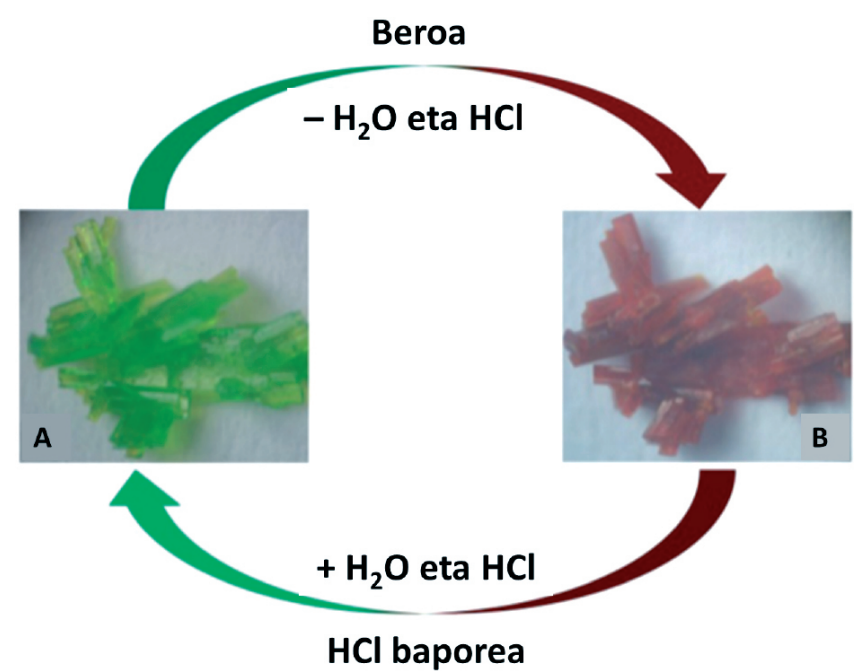

1. irudia. MKMK trantsizio bidezko $\left(\mathrm{H}_{3} \mathrm{O}\right)[\mathrm{K}(15-\mathrm{zi}-$ kloeter-5) $\left.{ }_{2}\right]\left[\mathrm{CuCl}_{4}\right]$ (berdea, A) eta $\left[\mathrm{K}\left(15\right.\right.$-zikloeter-5) $\left.{ }_{2}\right]$ $\left[\mathrm{CuCl}_{3}\right]$ (gorria, B) espezieen arteko eraldaketa. Gezietan transformazioa eragiten duen kanpo estimulua adierazten da [8].

Hala ere, sarritan, MOF egituren malgutasunaren ondorioz, sistema ez da monokristal izaera mantentzeko gai eta kanpo-estimuluaren aplikazioak egitura kristalinoaren kolapsoa dakar. Hau saihesteko, egituraren irmotasuna areagotzen duten elementuak txertatzea metodo baliagarria dela frogatu da. Helburu hori bete dezaketen espezie kimikoen artean, polioxometalatoak (POMak) aurkitu ditzakegu. 
Leticia Fernández-Navarro, Estibaliz Ruiz-Bilbao, Beñat Artetxe, Leire San Felices, Amaia Iturrospe, Santiago Reinoso

\section{MKMk TRANTSIZIOAK POM-etan}

Aurreko lan batean azaltzen genuen legez [11], POMak metal eta oxigenoz osatutako kluster anionikoak dira, oro har, $\mathrm{MO}_{x}(x=4-6)$ motako poliedroen kondentsazio azidotik eratorriak $(\mathrm{M}=\mathrm{V}$, Mo edo $\mathrm{W}$, oxidazio zenbaki altuenetan) [12]. Konposizioari dagokionez, POMak bi talde nagusitan sailkatzen dira: metal eta oxigenoz bakarrik osatutakoak (isoPOMak) eta metal eta oxigenoaz gain, heteroatomo (X) izeneko atomo gehigarriak $(\mathrm{X}=\mathrm{Si}, \mathrm{P}, \mathrm{Ge} . .$.$) aurkezten dituztenak (heteroPOMak). Azaldu ohi du-$ ten egitura (2. irudia), konposizio- eta propietate-aniztasunaren ondorioz, POMek aplikazio ugari dituzte teknologian, edo ingurugiroari lotutako arloetan; besteak beste, katalisian [13], magnetismoan [14], biomedikuntzan [15] eta oro har, materialen zientziaren arloan [16].

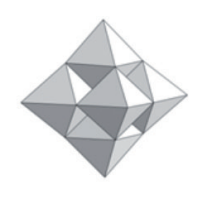

$$
\mathrm{M}_{6} \mathrm{O}_{19}
$$
Lindquist

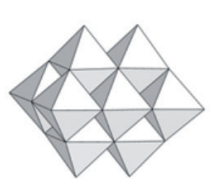

$\mathrm{M}_{10} \mathrm{O}_{28}$
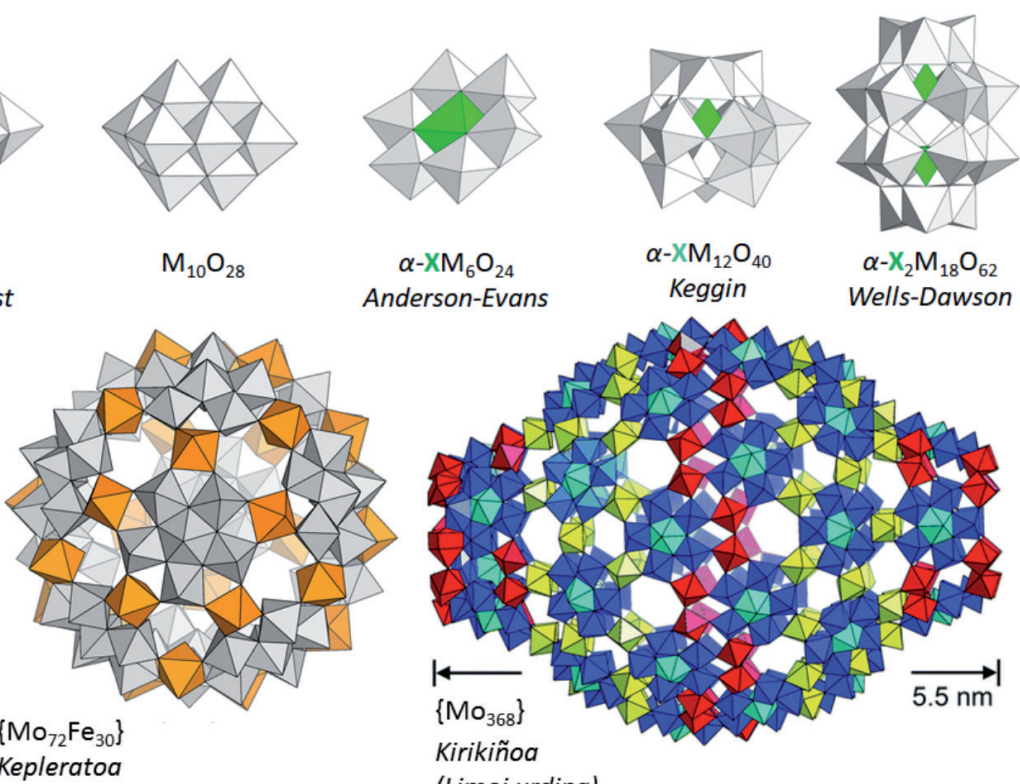

$$
\underset{\text { Keggin }}{\alpha-\mathrm{M}_{12} \mathrm{O}_{40}}
$$

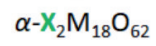

Wells-Dawson

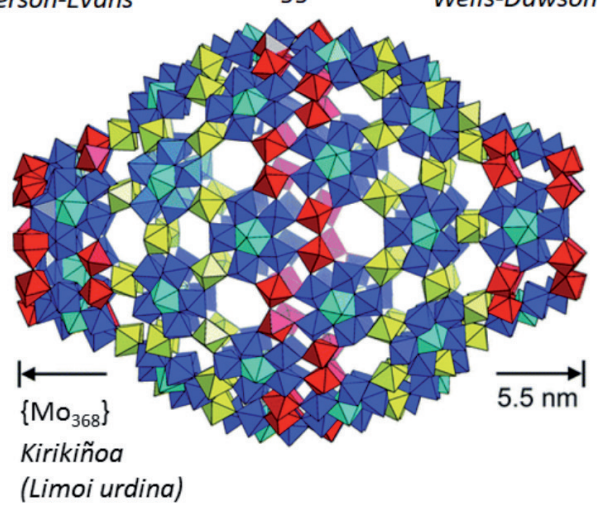

(Limoi urdina)

2. irudia. POMen esparruko ohiko egituren zenbait adibide. Kolore-kodea: $\left\{\mathrm{MO}_{6}\right\}$ oktaedro grisa, $\left\{\mathrm{XO}_{\mathrm{n}}\right\}$ poliedro berdea, $\left\{\mathrm{FeO}_{6}\right\}$ oktaedro laranja. Balentzia desberdinetako molibdeno zentroak kolore desberdinetan agertzen dira.

MKMK trantsizioek POMen esparruko ikerketa arlo berri bat osatzen dutenez, orain arte, propietate hau aurkezteko gai diren POMetan oinarritutako 28 egitura baino ez dira ezagutzen [17]. Haien artean, tenperatura-aldaketek eragindako trantsizioez gain, beste zenbait kanpo estimuluk aktibatutako sistemak aztertu dira; hala nola, oxidazio-erredukzio proze- 
suen [18], argiaren [19] edo espezie kimiko desberdinen akzioaren ondorioz [20] gertatzen direnak. Lehen adibidea Mizunoren taldeak argitaratu zuen 2005ean. Ikerketa taldeko kideak gai izan ziren $\mathrm{X}$ izpien difrakzioaren bidez $\mathrm{Cs}_{5}\left[\mathrm{Cr}_{3} \mathrm{O}(\mathrm{OOCH})_{6}\left(\mathrm{H}_{2} \mathrm{O}\right)_{3}\right]\left[\mathrm{CoW}_{12} \mathrm{O}_{40}\right] \cdot 7.5 \mathrm{H}_{2} \mathrm{O}$ konposatuak jasan dezakeen termikoki aktibatutako deshidratazio partzial itzulgarria aztertzeko. Transformazio honetan, ez da egitura-aldaketa nabarmenik gertatzen eta konposatuak porotsua izaten jarraitzen du makro-katioi $\left(\left[\mathrm{Cr}_{3} \mathrm{O}(\mathrm{OOCH})_{6}\left(\mathrm{H}_{2} \mathrm{O}\right)_{3}\right]^{+}\right)$eta Keggin motako POMen $\left(\left[\mathrm{CoW}_{12} \mathrm{O}_{40}\right]^{6-}\right)$ paketatze ez-eraginkorraren ondorioz. Beraz, sistema honen ezaugarri nagusia etanola edo metanola bezalako beste molekula polar batzuen aurrean ura modu selektibo eta itzulgarrian xurgatzeko ahalmenean datza. Honela, alkohol hauen nahasteetan egon daitezkeen ur-arrasto txikiak kentzeko erabil liteke [21]. Ordutik hona, ikusi da POMetan oinarritutako hainbat sistema gai direla MKMK trantsizioak jasateko: a) guztiz ezorganikoak diren konposatuak (adibidez, $\mathrm{H}_{5} \mathrm{PV}_{2} \mathrm{Mo}_{10} \mathrm{O}_{40} \cdot 8 \mathrm{H}_{2} \mathrm{O}$ [22]), b) molekula organikoak dituzten konposatuak $\left((\mathrm{TBA})_{4}\left[\mathrm{SiV}_{2} \mathrm{~W}_{10} \mathrm{O}_{39}\right] \cdot 2 \mathrm{DCE}\right.$, non $\mathrm{TBA}=$ tetrabutilamonio eta $\mathrm{DCE}=1,2$-dikloroetanoa [23]), eta c) POM anioi eta konplexu metal-organikoen konbinazioz prestatutako konposatu hibridoak (adibidez, $\left[\mathrm{Co}(\mathrm{Hbpe})_{2}\left(\mathrm{~V}_{4} \mathrm{O}_{12}\right)\right]$, non bpe = bipiridiletenoa [24]).

Azken konposatu hibrido hauetan zentratuz, azkenaldian, POM eta estekatzaile zikliko N4-tetrahorzdunetan oinarritutako metal-konplexuen arteko erreakzioak MKMK trantsizioak jasateko gai diren konposatu interesgarri ugari prestatzeko bidea direla ikusi da. Hasiera batean estrategia hau sare porotsuak lortzeko bide gisa diseinatu zen, estekatzaile ziklikoak gai baitira trantsizio-metalaren inguruko posizio ekuatorialak blokeatzeko eta axialak eskuragarri uzteko, bata bestearen ondoan dauden klusterren gainazalarekin elkarrekin eta bien arteko zubi lana burutu ahal izateko. Hala ere, gerora, MKMK trantsizioak aurkezten dituzten sistemen iturri ezin hobea direla frogatu zen, konplexuak gai baitira erraz apurtu eta sortzen diren molekula-arteko interakzio ahulen bidez (adibidez, hidrogeno lotura ahulak), kristalinitatearen galera saihesteko. Mota honetako estekatzaileak eta metalak har ditzakeen koordinazio-geometria ezberdinak 3. irudian bildu dira.

POMetan oinarritutako konposatuetan erregistratutako MKMK trantsizio gehienak tenperatura aldaketa batek eragindakoak dira [25]. Oro har, tenperaturaren igoerak konposatuko disolbatzaile molekulen galera dakar eta, ondorioz, materialaren propietateren baten aldaketa eragin dezaketen egitura-aldaketak gertatzen dira. 
Leticia Fernández-Navarro, Estibaliz Ruiz-Bilbao, Beñat Artetxe,

Leire San Felices, Amaia Iturrospe, Santiago Reinoso

(a)<smiles>C1CNCCNCCNCCNC1</smiles>

Cyclam: 1,4,8,11-tetraazaziklotetradekanoa

(c)<smiles>CN(CCN(C)Cc1ccccn1)Cc1ccccn1</smiles>

(b)<smiles>C1CNCCNCCNCCNC1</smiles>

Cyclen: 1,4,7,10-tetraazaziklotetradodekanoa

(d)<smiles>CN(CCCCN(C)Cc1ccccn1)Cc1ccccn1</smiles>

bpmen: N, N'-Dimetil-N, $N^{\prime}$-bis-(piridin-2-ilmetil)1,2-diaminoetanoa

bpmpn: N, N'-Dimetil-N, N'-bis-(piridin-2-ilmetil)1,2-diaminopropanoa

(e)

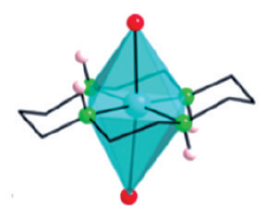

$\mathrm{MN}_{4} \mathrm{O}_{\text {POM2 }}$

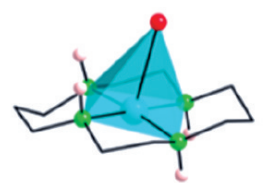

$\mathrm{MN}_{4} \mathrm{O}_{\text {pOM }}$

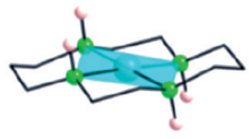

$\mathrm{MN}_{4}$

3. irudia. Ohiko estekatzaile N4-tetrahorzdunen adibideak: (a) cyclam, (b) cyclen, (c) bpmen eta (d) bpmpn. (e) Metalak har ditzakeen koordinazio modu ezberdinak: koordinazio oktaedrikoa (ezkerrean), piramide karratua (erdian) eta karratu laua (eskuman).

\section{TERMIKOKI AKTIBATUTAKO MKMK ERALDAKETAK POM-etan OINARRITUTAKO SISTEMETAN}

Gure ikerkuntza taldeak argitaratu dituen termikoki aktibatutako MKMK trantsizioak eta konposatu ezberdinen formula kimikoak 1. taulan laburbildu dira. Kasu guztietan, POM eta estekatzaile zikliko N4-tetrahorzdunetan oinarritutako metal-konplexuen konbinazioz eratutako konposatu hibridoak dira. Sistema hauek berotzean deshidratazio-prozesu bat jasaten dute, egitura eta propietate ezberdinen aldaketa dakarrena. Hurrengo ataletan, sistema bakoitzaren deskribapen zehatza emango da eta haien aplikazio nagusiak aipatuko dira. 
Monokristal-monokristal eraldaketak polioxometalatoetan oinarritutako sistemetan: termikoki aktibatutako zenbait adibide

1. taula. Termikoki aktibatutako MKMK eraldaketak POMetan oinarritutako sistema hibridoetan.

\begin{tabular}{|c|c|}
\hline Konposatua & MKMK trantsizioa \\
\hline $\begin{array}{c}\text { 1: }\left[\mathrm{Cu}(\text { bpmen })\left(\mathrm{H}_{2} \mathrm{O}\right)\right]\left[\mathrm{SiW}_{12} \mathrm{O}_{40}\{\mathrm{Cu}(\text { bpmen })\}\right] \\
\text { 1a: }\left[\mathrm{SiW}_{12} \mathrm{O}_{40}\{\mathrm{Cu}(\text { bpmen })\}_{2}\right] \\
\text { 2: }\left[\mathrm{Cu}(\text { bpmen })\left(\mathrm{H}_{2} \mathrm{O}\right)\right]\left[\mathrm{GeW}_{12} \mathrm{O}_{40}\{\mathrm{Cu}(\text { bpmen })\}\right] \cdot 3.5 \mathrm{H}_{2} \mathrm{O} \\
\text { 2a: }\left[\mathrm{GeW}_{12} \mathrm{O}_{40}\{\mathrm{Cu}(\text { bpmen })\}_{2}\right]\end{array}$ & $\begin{array}{l}\text { Konplexuen koordinazioa } \\
\text { POMaren gainazalera }\end{array}$ \\
\hline $\begin{array}{l}\text { 3: }\left[\mathrm{SiW}_{12} \mathrm{O}_{40}\left\{\mathrm{Cu}(\text { bpmpn })\left(\mathrm{H}_{2} \mathrm{O}\right)\right\}_{2}\right] \cdot 3 \mathrm{H}_{2} \mathrm{O} \\
\text { 3a: }\left[\mathrm{SiW}_{12} \mathrm{O}_{40}\{\mathrm{Cu}(\text { bpmpn })\}_{2}\right] \\
\text { 4: }\left[\mathrm{GeW}_{12} \mathrm{O}_{40}\left\{\mathrm{Cu}(\text { bpmpn })\left(\mathrm{H}_{2} \mathrm{O}\right)\right\}_{2}\right] \cdot 3 \mathrm{H}_{2} \mathrm{O} \\
\text { 4a: }\left[\mathrm{GeW}_{12} \mathrm{O}_{40}\{\mathrm{Cu}(\text { bpmpn })\}_{2}\right]\end{array}$ & $\begin{array}{l}\text { Aldaketak estekatzailearen } \\
\text { konformazioan eta } \mathrm{Cu}^{\mathrm{II}} \text {-aren } \\
\text { koordinazioan }\end{array}$ \\
\hline $\begin{array}{c}\text { 5: }\left[\{\mathrm{Cu}(\text { cyclam })\}\left(\mathrm{VO}_{3}\right)_{2}\right] \cdot 5 \mathrm{H}_{2} \mathrm{O} \\
\text { 5a: }\left[\{\mathrm{Cu}(\text { cyclam })\}\left(\mathrm{VO}_{3}\right)_{2}\right] \cdot 3 \mathrm{H}_{2} \mathrm{O} \\
\text { 5b: }\left[\{\mathrm{Cu}(\text { cyclam })\}\left(\mathrm{VO}_{3}\right)_{2}\right] \cdot 1.3 \mathrm{H}_{2} \mathrm{O} \\
\text { 5c: }\left[\{\mathrm{Cu}(\text { cyclam })\}\left(\mathrm{VO}_{3}\right)_{2}\right]\end{array}$ & $\begin{array}{l}\text { Metabanadato kateen konfigurazio } \\
\text { aldaketa eta porositatearen } \\
\text { murrizketa dakarren deshidratazio } \\
\text { itzulgarri eta sekuentziala }\end{array}$ \\
\hline $\begin{array}{c}\text { 6: }[\mathrm{Cu}(\text { cyclam })]\left[\{\mathrm{Cu}(\text { cyclam })\}_{2}\left(\mathrm{~V}_{10} \mathrm{O}_{28}\right)\right] \cdot 10 \mathrm{H}_{2} \mathrm{O} \\
\quad \text { 6a: }[\mathrm{Cu}(\text { cyclam })]\left[\{\mathrm{Cu}(\text { cyclam })\}_{2}\left(\mathrm{~V}_{10} \mathrm{O}_{28}\right)\right]\end{array}$ & Egitura irmo eta porotsua \\
\hline $\begin{array}{c}\text { 7: }\left[\{\mathrm{Cu}(\text { cyclam })\}_{2}\left[\mathrm{Mo}_{8} \mathrm{O}_{26}\right] \cdot 1.5 \mathrm{H}_{2} \mathrm{O}\right. \\
\text { 7a: }\left[\{\mathrm{Cu}(\text { cyclam })\}_{2}\left[\mathrm{Mo}_{8} \mathrm{O}_{26}\right]\right.\end{array}$ & Egitura irmoa \\
\hline $\begin{array}{c}\text { 8: }\left[\{\mathrm{Cu}(\text { cyclam })\}_{3}\left(\mathrm{~W}_{7} \mathrm{O}_{24}\right)\right] \cdot 15.5 \mathrm{H}_{2} \mathrm{O} \\
\text { 8a: }\left[\{\mathrm{Cu}(\text { cyclam })\}_{3}\left(\mathrm{~W}_{7} \mathrm{O}_{24}\right)\right] \cdot 12 \mathrm{H}_{2} \mathrm{O} \\
\text { 8b: }[\mathrm{Cu}(\text { cyclam })]_{0.5}\left[\{\mathrm{Cu}(\text { cyclam })\}_{2.5}\left(\mathrm{~W}_{7} \mathrm{O}_{24}\right)\right]\end{array}$ & $\begin{array}{l}\text { Egitura porotsu dinamikoa: } \mathrm{Cu}^{\mathrm{II}} \\
\text { ezberdinen koordinazio aldaketak }\end{array}$ \\
\hline
\end{tabular}

\subsection{POM-Cu[bis(aminopiridilo)] sistema}

Bis(aminopiridilo) motako estekatzaile N4-tetrahorzdunen konplexuen eta Keggin motako anioien $\left[\mathrm{XW}_{12} \mathrm{O}_{40}\right]^{4-}(\mathrm{X}=\mathrm{Si}, \mathrm{Ge})$ konbinazioaz, MKMK trantsizioak jasateko gai diren konposatu molekularrak lortzen dira. 3. irudian aipatu diren bpmen eta bpmpn estekatzaileen $\mathrm{Cu}^{\mathrm{II}}$ konplexuak erabiliz gero [26, 27], bi fenomeno desberdin gertatzen dira konposatu hidratatuaren ur molekulak termikoki galtzean.

Batetik, bpmen estekatzailetik hasita presta daitezkeen $[\mathrm{Cu}($ bpmen) $\left.\left(\mathrm{H}_{2} \mathrm{O}\right)\right]-\left[\mathrm{SiW}_{12} \mathrm{O}_{40}\{\mathrm{Cu}(\right.$ bpmen $\left.)\}\right](\mathbf{1})$ eta $\left[\mathrm{Cu}(\right.$ bpmen $\left.)\left(\mathrm{H}_{2} \mathrm{O}\right)\right]\left[\mathrm{GeW}_{12} \mathrm{O}_{40}\right.$ $\{\mathrm{Cu}($ bpmen $)\}] \cdot 3.5 \mathrm{H}_{2} \mathrm{O}(2)$ konposatuen egiturak, Keggin motako anioi baten gainazalera koordinatutako $\{\mathrm{Cu}(\text { bpmen })\}^{2+}$ konplexua eta karga konpentsazio lana burutzen duen $\left[\mathrm{Cu}(\text { bpmen })\left(\mathrm{H}_{2} \mathrm{O}\right)\right]^{2+}$ espezie hidratatuaz eratuta daude. Tenperatura igoerak MKMK bidezko eraldaketa aktibatzen du eta konplexu hidratatua POMaren gainazalera lotzen da ur molekula apikala galtzen duenean (4. irudia). Konposatuaren deshidratazioa itzulgarria 
Leticia Fernández-Navarro, Estibaliz Ruiz-Bilbao, Beñat Artetxe, Leire San Felices, Amaia Iturrospe, Santiago Reinoso

da eta rehidratazioa azkar (1h-tan) gertatzen da kristalek atmosferako hezetasuna xurgatzen dutenean.
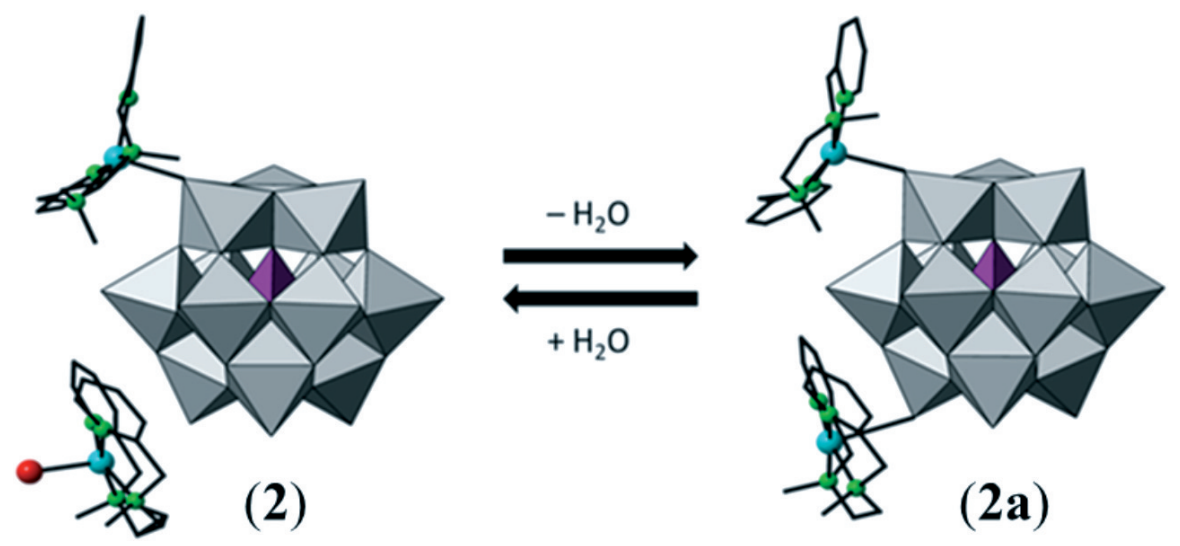

4. irudia. 2 konposatuan ematen den MKMK eraldaketaren errepresentazio eskematikoa. Kolore-kodea: $\left\{\mathrm{WO}_{6}\right\}$ oktaedro grisa, $\left\{\mathrm{GeO}_{4}\right\}$ tetraedro larrosa; C, beltza; $\mathrm{Cu}$, urdina; $\mathrm{N}$, berdea; ur molekula, gorria. $\mathrm{H}$ atomoak ez dira errepresentatu.

Bestetik, bpmpn estekatzailea erabiliz prestatutako $\left[\mathrm{XW}_{12} \mathrm{O}_{40}\right.$ $\left.\left\{\mathrm{Cu}(\text { bpmpn })\left(\mathrm{H}_{2} \mathrm{O}\right)\right\}_{2}\right] \cdot 3 \mathrm{H}_{2} \mathrm{O}(\mathrm{X}=\mathrm{Si}, 3 ; \mathrm{X}=\mathrm{Ge}, 4)$ konposatuen kasuan, egitura molekularra Keggin anioiaren gainazalera koordinatutako bi $\left[\mathrm{Cu}(\text { bpmpn })\left(\mathrm{H}_{2} \mathrm{O}\right)\right]^{2+}$ konplexuz eratuta dago. MKMK bidezko deshidratazioan, konplexuen ur molekula axialak galdu eta estekatzaileen konformazio-aldaketa gertatzen da. Hots, 5. irudian ikus daitekeen moduan, metilo taldeen kokapen erlatiboa trans (metilo taldeetako bakoitza estekatzailearen planoaren alde batean dago) egoeratik, cis egoerara (bi metilo taldeak estekatzailearen planoaren alde berean daude) pasatzen da.
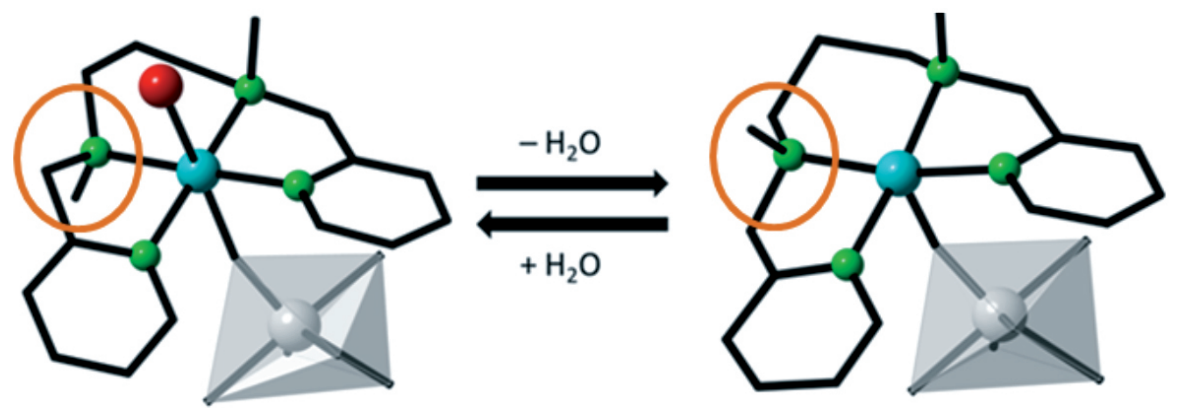

5. irudia. $\mathbf{3}$ eta $\mathbf{4}$ konposatuetan ematen den MKMK eraldaketaren errepresentazio eskematikoa. 
Monokristal-monokristal eraldaketak polioxometalatoetan oinarritutako sistemetan: termikoki aktibatutako zenbait adibide

\subsection{POM-Cu(cyclam) sistemak}

Ordezkatzaileen ausentziak eta hidrogeno loturak eratzeko ahalmenak, 1,4,8,11-tetraazaziklotetradekanoa (cyclam) estekatzaile bikaina izan daitekeela aurresaten dute termikoki aktibatutako MKMK trantsizioak jasan dezaketen konposatuak sintetizatzerakoan. Atal honetan estekatzaile honen $\mathrm{Cu}$ (II) konplexuetan eta hiru isoPOM familia ezberdinetan jarriko dugu arreta: polioxobanadatoak, polioxomolibdatoak eta polioxowolframatoak.

\subsubsection{Polioxobanadatoak}

Banadato ioien eta $\{\mathrm{Cu}(\text { cyclam })\}^{2+}$ konplexuen arteko erreaktibitatea aztertzean, egitura porotsua duten bi konposatu ezberdin isola daitezke ingurune urtsuaren pHaren arabera. Ingurune basikoan $(\mathrm{pH}=9)$ metabanadato kateetan oinarritutako $\left[\{\mathrm{Cu}(\right.$ cyclam $\left.)\}\left(\mathrm{VO}_{3}\right)_{2}\right] \cdot 5 \mathrm{H}_{2} \mathrm{O}$ (5) konposatua isolatzen den bitartean, arinki azidoa den ingurunean $(\mathrm{pH}=4-6)$ dekabanadato klusterretan oinarritutako $[\mathrm{Cu}($ cyclam $)]\left[\{\mathrm{Cu}(\text { cyclam })\}_{2}\right.$ $\left.\left(\mathrm{V}_{10} \mathrm{O}_{28}\right)\right] \cdot 10 \mathrm{H}_{2} \mathrm{O}(6)$ sarea lor daiteke.

Lehenaren egituran, erpinak partekatzen dituzten $\left(\mathrm{VO}_{4}\right)^{3-}$ unitateen errepikapenez eratutako metabanadato kateak $\{\mathrm{Cu}(\text { cyclam })\}^{2+}$ konplexuen koordinazioaren bidez lotzen dira eta hirudimentsioko egitura porotsua eratzen dute. Kanaletan hidratazio ur molekula guztiak kokatzen dira. Konposatu honen kristalak berotzerakoan, izaera dinamikoa duten 3 faseeraldaketa itzulgarri ezberdin aurki ditzakegu hidratazio mailaren arabera. Trantsizio horiek aldaketa sakonak dakartzate metabanadato kateen konfigurazioan eta $\mathrm{Cu}^{\mathrm{II}}$ zentroen koordinazioan. Tamalez, disolbatzailearen galerak poro tamainaren murrizketa dakar eta horren ondorioz, $[\{\mathrm{Cu}($ cyclam $)\}$ $\left.\left(\mathrm{VO}_{3}\right)_{2}\right](\mathbf{5 c})$ fase anhidroak ez du inolako funtzionalitaterik aurkeztuko gasen adsortzioan [28].

Dekabanadato anioian oinarritutako $[\mathrm{Cu}($ cyclam $)]\left[\{\mathrm{Cu}(\text { cyclam })\}_{2}\right.$ $\left.\left(\mathrm{V}_{10} \mathrm{O}_{28}\right)\right] \cdot 10 \mathrm{H}_{2} \mathrm{O}(6)$ konposatuan, klusterretako bakoitza aldameneko beste lau unitateri lotzen zaio $\{\mathrm{Cu}(\text { cyclam })\}^{2+}$ konplexuen koordinazioaren bidez. Geruza hauen artean, karratu lauak diren konplexu kationikoak kokatzen dira. Elementu hauen guztien pilaketak porotsua den sarea osatzen $\mathrm{du}$, non hidratazio ur molekulak kanal isolatuetan aurki ditzakegun. Beroa aplikatzean, disolbatzaile molekula hauek galdu egiten dira, guztiz irmoa den MKMK trantsizio baten bidez; hots, sare kristalinoa ez da ia aldatzen eta kanalek berdintsuak izaten jarraitzen dute (6. irudia). Hutsik dauden kanalen tamaina ikusita, $\mathrm{N}_{2}$ eta $\mathrm{CO}_{2}$ gasen adsortzioa aztertzea erabaki zen. Ikerketek hauxe azaleratu zuten: konposatu anhidroa gai da negutegi efektuaren erantzule den $\mathrm{CO}_{2}$-a selektiboki adsorbatzeko $\mathrm{N}_{2}$-aren aurrean. Gainera, sare honek bereziki egonkorra den adamantano alkano triziklikoaren oxidazio heterogeneoa katalizatzen zuela ikusi zen [29]. 


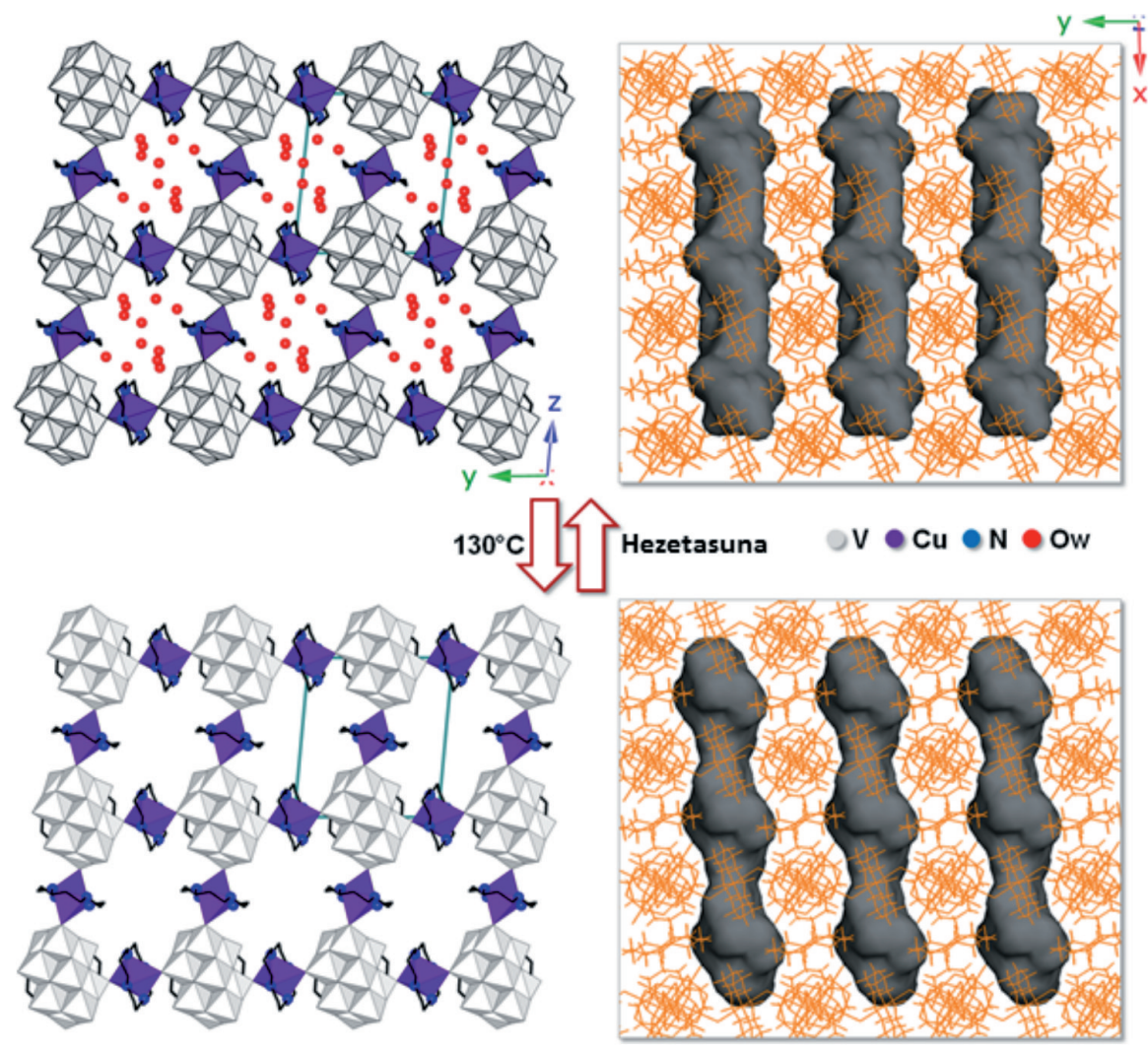

6. irudia. 6 konposatuan ematen den MKMK eraldaketa itzulgarriaren eskema, konposatu anhidroaren kanal hutsen errepresentazioarekin batera. $\mathrm{O}_{\mathrm{w}}=$ ur molekula.

\subsubsection{Polioxomolibdatoak}

Baldintza hidrotermaletan (ontzi itxi batean eta uraren irakite-puntutik gorako tenperaturan sortzen den presio autogenoa aprobetxatuz) gertatzen den molibdato-iturri baten eta $\{\mathrm{Cu}(\text { cyclam })\}^{2+}$ konplexuen arteko erreakzioaren emaitza, egituraren aldetik askoz trinkoagoa den $\left[\{\mathrm{Cu}(\text { cyclam })\}_{2}\right.$ $\left[\mathrm{Mo}_{8} \mathrm{O}_{26}\right] \cdot 1.5 \mathrm{H}_{2} \mathrm{O}(7)$ konposatua da [30]. Han, $\gamma-\left\{\mathrm{Mo}_{8} \mathrm{O}_{26}\right\}$ unitateak kobalenteki lotzen dira $\left[\mathrm{Mo}_{8} \mathrm{O}_{26}\right]_{n}$ kate-egitura polimerikoa osatzeko. Konplexu metal-organikoek bata bestearen aldamenean kokatutako kateak lotzen dituzte eta, horren ondorioz, porotsua den egitura tridimentsionala eratzen da. Hain da trinkoa egitura, ezen, kristala berotu eta hutsuneetan kokatutako hidratazio-ur molekulak galtzean, ez baita inolako aldaketarik ikusten. Hala ere, poroen tamaina txikiak ez du gasen adsortziorako aukera handiegirik uzten (7. irudia). 


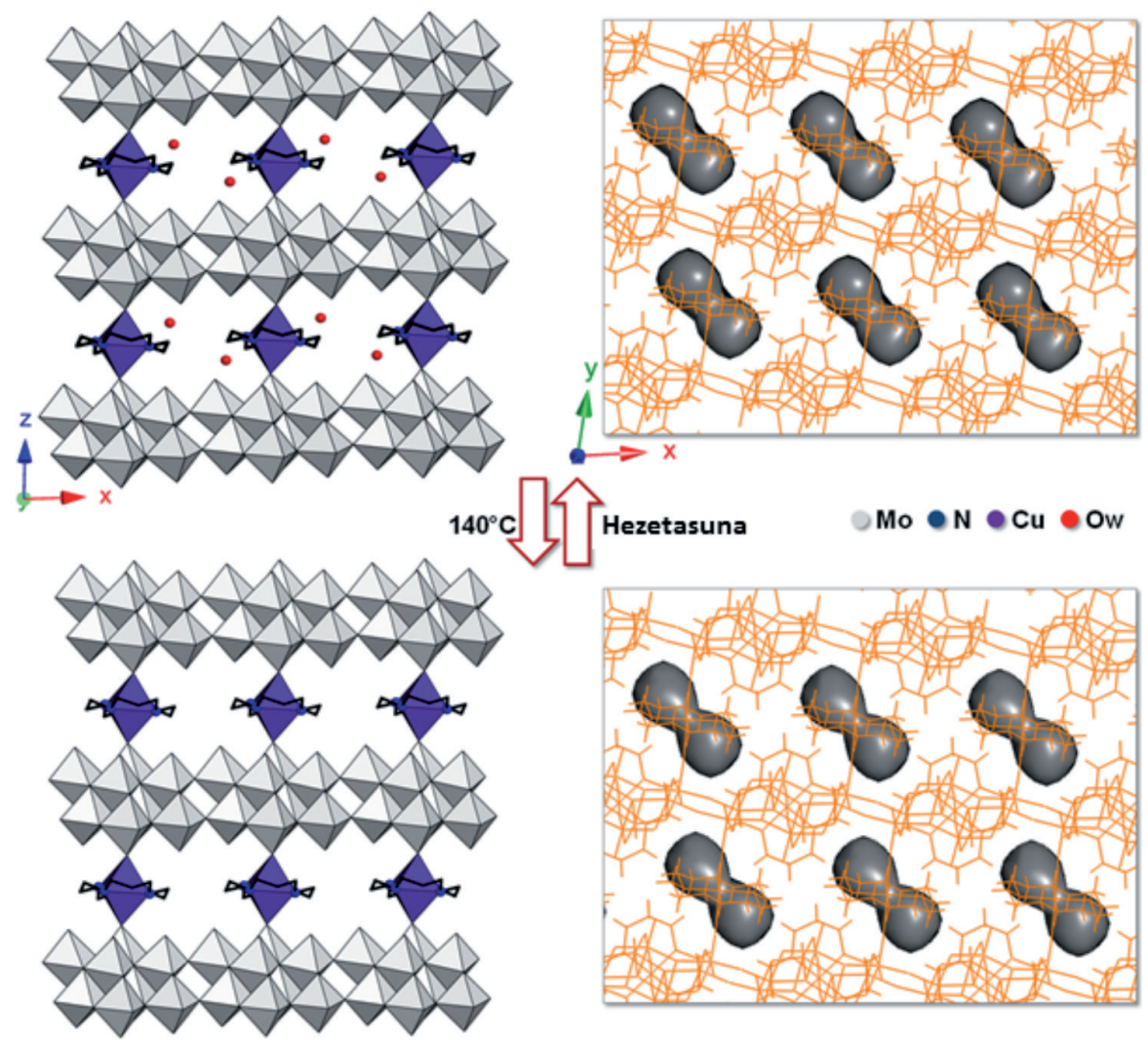

7. irudia. 7 konposatuan gertatzen den MKMK eraldaketa itzulgarriaren eskema, konposatu anhidroaren kanal hutsen errepresentazioarekin batera.

\subsubsection{Polioxowolframatoak}

Aipatu berri dugun ikerketa wolframatoetara hedatzean, $\left[\{\mathrm{Cu}(\text { cyclam })\}_{3}\right.$ $\left.\left(\mathrm{W}_{7} \mathrm{O}_{24}\right)\right] \cdot 15.5 \mathrm{H}_{2} \mathrm{O}(8)$ formuladun hibridoa lortzen da. Konposatu honetan, heptawolframato anioietako bakoitza aldameneko sei unitateri lotzen zaio $\{\mathrm{Cu}(\text { cyclam })\}^{2+}$ espezieen bidez, hiru dimentsioko egitura porotsua eratuz. Elkargurutzatutako kanaletan hidratazio ur molekulak kokatzen dira [31]. Sistema berotzean bi MKMK trantsizio dinamiko gertatzen dira baina, metabanadato-kateetan oinarritutako sisteman ez bezala, kasu honetan ur gabeko egiturak porotsua izaten jarraitzen du. Hala ere, kanalen arteko konexioa galdu egiten da tenperatura altuko egituran. Horrela, $60^{\circ} \mathrm{C}$-tan partzialki deshidratatutako $\left[\{\mathrm{Cu}(\text { cyclam })\}_{3}\left(\mathrm{~W}_{7} \mathrm{O}_{24}\right)\right] \cdot 12 \mathrm{H}_{2} \mathrm{O}(\mathbf{8 a})$ lortzen den bitartean, $120{ }^{\circ} \mathrm{C}$-tan $[\mathrm{Cu}(\text { cyclam })]_{0.5}\left[\{\mathrm{Cu}(\text { cyclam })\}_{2}\left(\mathrm{~W}_{7} \mathrm{O}_{24}\right)\right]$ (8b) egitura anhidroa lortzen da. Eraldaketa hauetan, aldaketa sakonak ger- 
Leticia Fernández-Navarro, Estibaliz Ruiz-Bilbao, Beñat Artetxe, Leire San Felices, Amaia Iturrospe, Santiago Reinoso

tatzen dira, besteak beste, konplexu metal-organikoen geometrian. Nabarmentzekoa da kasu honetan sistemaren itzulgarritasuna. Fase anhidroa (8b) gai da partzialki hidratatutako formara (8a) bueltatzeko; aldiz, azken hau ez da inolaz ere hasierako fase hidratatura (8) bueltatzen (8. irudia).
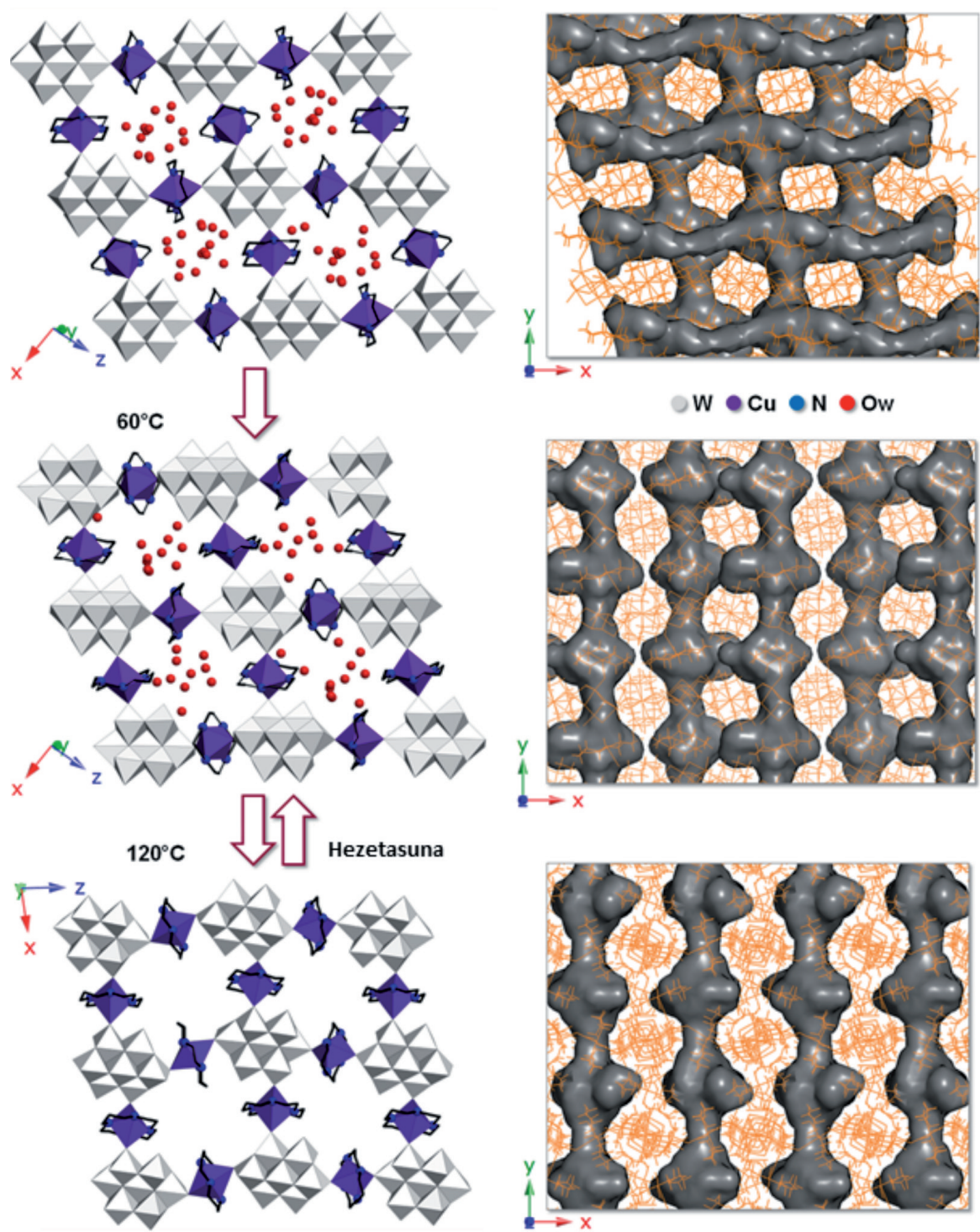

$\mathrm{W} \bullet \mathrm{Cu} \bullet \mathrm{N} \bullet \mathrm{OW}$
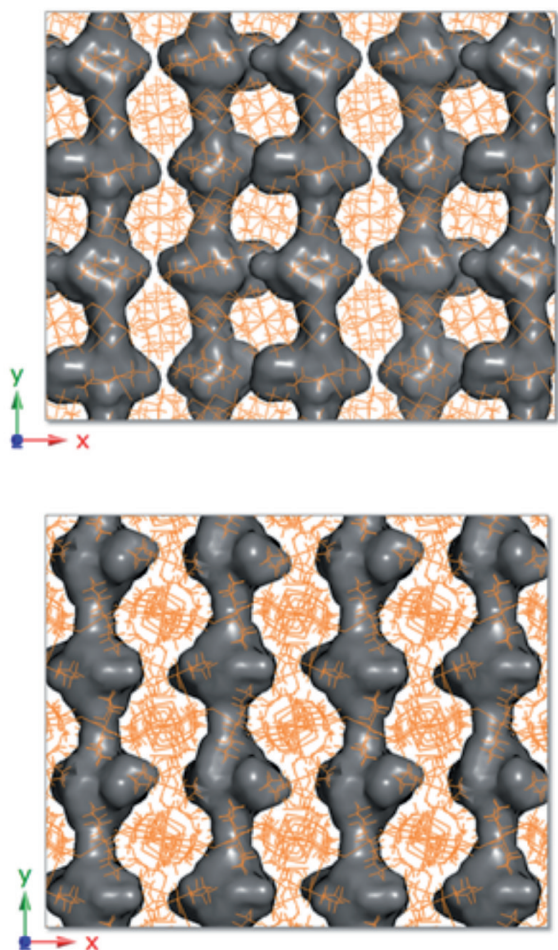

8. irudia. 8 konposatuan gertatzen den MKMK eraldaketaren adierazpen eskematikoa, itzulgarritasuna eta konposatu anhidroaren kanal hutsen errepresentazioarekin batera. 
Azkenik, egitura anhidroa porotsua zela ikusita, gasen xurgapenerako sistema gisa aztertu zen. Ikerketek erakutsi zuten $\mathrm{CO}_{2}$ eta $\mathrm{N}_{2}$ gasak adsorbatzeko gai zela . Ondorioz, konposatu hau, lehenengo aldiz POM eta metal-konplexuen konbinazioz osatutako egituren artean, gai da aldi berean a) termikoki induzitutako MKMK trantsizio dinamiko bat jasateko eta b) aurkezten duen mikroporositatearen bidez gas mota ezberdinak adsorbatzeko.

\section{ONDORIOAK}

Lan honetan zehar MKMK fase trantsizioak jasaten dituzten POMei atxikitutako metal-konplexuetan oinarritutako konposatuen adibide batzuk aipatu dira. Horrela, hasiera batean propietate berezirik edo erabilgarritasun argirik ez zuten konposatuek gasak selektiboki xurgatzeko edota katalizatzaile gisa jokatzeko ahalmena aurkeztu dute fase trantsizioetatik eratorritako aldaketen ondorioz. POMak bezalako oinarrizko unitate zurrunak erabiltzea bide egokia dela frogatu da, prozesuan zehar gerta litekeen kristalinitatearen galera saihesteko. Kobre(II) ioietan eta estekatzaile N4-tetrahorzdunetan oinarritutako konplexuak POM ezberdinekin konbinatzean, MKMK trantsizioak jasan ditzaketen hainbat konposatu sintetizatu dira. Batetik, 1-4 konposatuetan Keggin anioia eta $\mathrm{Cu}$ [bis(aminopiridilo)] konplexuak elkartzean, gai izan gara MKMK eraldaketen emaitza gisa i) konplexuen koordinazioan eta ii) estekatzaileen konformazioan aldaketak ikusteko. Bestetik, $\{\mathrm{Cu}(\text { cyclam })\}^{2+}$ konplexuen erabilerak, honako behaketa hauek ahalbidetu ditu: a) 5 konposatuan, porositatearen murrizketa dakarren deshidratazio dinamiko, itzulgarri eta sekuentziala; b) dekabanadato eta oktamolibdato anioiekin batera (6 eta 7 konposatuak) konbinatzean, egitura irmo eta porotsuen eraketa; eta c) $\mathbf{8}$ konposatuko eraldaketa dinamikoak, porositate iraunkorra duen egitura anhidroa lortzeko bidea direna. Nabarmentzekoak dira 6a eta 8a egitura anhidro porotsuen propietateak: lehena gai da negutegi efektuaren erantzule den $\mathrm{CO}_{2}$ selektiboki adsorbatzeko $\mathrm{N}_{2}$-aren aurrean eta bereziki egonkorrak diren alkano triziklikoen oxidazio heterogeneoa katalizatzeko. Bigarrenak $\mathrm{CO}_{2}$ eta $\mathrm{N}_{2}$ gasak adsorba ditzake.

Gaur egun, termikoki aktibatutako adibideak gailentzen badira ere, etorkizunean, propietate ezberdinak (kolorea, lumineszentzia, magnetismoa...) dituzten POM anioi eta konplexu kationikoekin jokatuz, gai izango gara trantsizioak aktibatzen dituzten kanpo-estimuluen (tenperaturaren, argiaren...) sentsoreak prestatzeko. Laburbilduz, ikerketa esparru honen lehen pausoetan bagaude ere, potentziala handia da zinez. 
Leticia Fernández-Navarro, Estibaliz Ruiz-Bilbao, Beñat Artetxe, Leire San Felices, Amaia Iturrospe, Santiago Reinoso

\section{ESKER ONAK}

Artikulu hau Eusko Jaurlaritzak Estibaliz Ruiz-Bilbaori eskainitako doktorego-aurreko diru-laguntzari esker (PRE_2018_1_0143) burutu da. Egileek UPV/EHU (PPG17/37, GIU17/050), Eusko Jaurlaritzaren (PIBA2018-59, KK-2018/00054) eta Ekonomia, Industria eta Lehiakortasun Ministerioaren (MAT2017-89553-P) finantziazioa eskertu nahi dute. Santiago Reinosok Obra Social la Caixa, Fundación Caja Navarra eta Nafarroako Unibertsitate Publikoaren «Captación de Talento» programaren bidez jasotako diru-laguntza eskertzen du.

\section{BIBLIOGRAFIA}

[1] CHAUDHARY, A., MOHAMMAD, A. eta MOBIN, S. M. 2017. «Recent advances in single-crystal-to-single-crystal transformation at the discrete molecular level». Crystal Growth \& Design, 17, 2893-2910.

[2] ZHANG, Y. J., LIU, T., KANEGAWA, S. eta SATO, O. 2009. «Reversible single-crystal-to-single-crystal transformation from achiral antiferromagnetic hexanuclear to a chiral ferrimagnetic double zigzag chain». Journal of the American Chemical Society, 131, 7942-7943.

[3] CORONADO, E. eta MíNGUEZ ESPALlargAS, G. 2013. «Dynamic magnetic MOFs». Chemical Society Reviews, 42, 1525-1539.

[4] NAKANISH, H.; JONES, W.; THOMAS, J.M.; HURSTHOUSE, M.B. eta MOTEVALLI, M. 1980. «Monitoring the crystallographic course of a single-crystal $\rightarrow$ single-crystal photodimerization by X-ray diffractometry». Journal of Chemical Society, Chemical Communications, 611-612.

[5] KE, S.-Y. eta WANG, C.-C. 2015. «Water-induced reversible SCSC or solid-state structural transformation in coordination polymers». CrystEngComm, 17, 8776-8785.

[6] HAO, Z.-M. eta ZHANG, X.-M. 2011. «Solvent induced molecular magnetic changes observed in single-crystal-to-single-crystal transformation». Dalton Transactions, 40, 2092-2098.

[7] CEPEDA, J. eta PÉREZ-YÁÑEZ, S. 2016. «Funtzio anitzeko polimero metal-organiko porotsuak (MOF): etorkizuneko material adimenduei begira». Ekaia, 31, 105-116.

[8] LI, N.- Y., LIU, D., REN, Z.-G., LOLLAR, C., LANG, J.-P. eta ZHOU, H.-C. 2018. «Controllable fluorescence switching of a coordination chain based on the photoinduced single-crystal-to-single-crystal reversible transformation of a syn-[2.2]metacyclophane». Inorganic Chemistry, 57, 849856.

[9] CAI, L.-Z., JIANG, X.-M., ZHANG, Z.-J., GUO, P.-Y., JIN, A.-P., WANG, M.-S. eta GUO, G.-C. 2017. «Reversible single-crystal-to-single-crystal transformation and magnetic change of nonporous copper(II) complexes by 
Monokristal-monokristal eraldaketak polioxometalatoetan oinarritutako sistemetan: termikoki aktibatutako zenbait adibide

the chemisorption/desorption of $\mathrm{HCl}$ and $\mathrm{H}_{2} \mathrm{O}$ ». Inorganic Chemistry, 56, 1036-1040.

[10] HE, Y.-C., YANG, J., LIU, Y.-Y. eta MA, J.-F. 2014. «Series of solvent-induced single-crystal to single-crystal transformations with different sizes of solvent molecules». Inorganic Chemistry, 53, 7527-7533.

[11] ARTETXE, B., REINOSO, S. eta GUTIÉRREZ-ZORRILLA, J. M. 2017. «Polioxometalatoak: Elhuyar anaien ametsak bizirik dirau!». Ekaia, 32, 97112.

[12] POPE, M. T. 1983. Heteropoly and Isopoly Oxometalates. Springer-Verlag, Berlin.

[13] NEUMANN, R. eta DAHAN, M. 1997. «A ruthenium-substituted polyoxometalate as an inorganic dioxygenase for activation of molecular oxygen». Nature, 388, 353-355.

[14] CLEMENTE-JUAN, J. M., CORONADO, E. eta GAITA-ARIÑO, A. 2012. «Magnetic polyoxometalates: from molecular magnetism to molecular spintronics and quantum computing». Chemical Society Reviews, 41, 7464-7478.

[15] HASENKNOPF, B. 2005. «Polyoxometalates: introduction to a class of inorganic compounds and their biomedical applications». Frontiers in Bioscience, 10, 275-287.

[16] SONG, Y.F. eta TSUNASHIMA, R. 2012. «Recent advances on polyoxometalate-based molecular and composite materials». Chemical Society Reviews, 41, 7384-7402.

[17] REINOSO, S., ARTETXE, B., SAN FELICES, L. eta GUTIÉRREZZORRILLA, J. M. 2016. Polyoxometalates: Properties, Structure and Synthesis. Nova Science Publishers, New York.

[18] THIEL, J.; RITCHIE, C.; STREB, C.; LONG, D.L. eta CRONIN, L. 2009. «Heteroatom-controlled kinetics of switchable polyoxometalate frameworks». Journal of the American Chemical Society, 131, 4180-4181.

[19] ZHANG, L.-Z.; GU, W.; DONG, Z. eta LING, B. 2008. «Solid-state photopolymerization of a photochromic hybrid based on Keggin tungstophosphates». CrystEngComm, 10, 652-654.

[20] EGUCHI, R., UCHIDA, S. eta MIZUNO, N. 2012. «Inverse and high $\mathrm{CO}_{2} /$ $\mathrm{C}_{2} \mathrm{H}_{2}$ sorption selectivity in flexible organic-inorganic ionic crystals». Angewandte Chemie International Edition, 51, 1635-1639.

[21] UCHIDA, S. eta MIZUNO, N. 2004. «Zeotype ionic crystal of $\mathrm{Cs}_{5}\left[\mathrm{Cr}_{3} \mathrm{O}(\mathrm{OOCH})_{6}\left(\mathrm{H}_{2} \mathrm{O}\right)_{3}\right]\left[\alpha-\mathrm{CoW}_{12} \mathrm{O}_{40}\right] \cdot 7.5 \mathrm{H}_{2} \mathrm{O}$ with shape-selective adsorption of water». Journal of the American Chemical Society, 126, 16021603.

[22] BARATS-DAMATOV, D., SHIMON, L. J. W., FELDMAN, Y., BENDIKOV, T. eta NEUMANN, R. 2015. «Solid-state crystal-to-crystal phase transitions and reversible structure-temperature behavior of phosphovanadomolybdic acid, $\mathrm{H}_{5} \mathrm{PV}_{2} \mathrm{Mo}_{10} \mathrm{O}_{40} \gg$. Inorganic Chemistry, 54, 628-634.

[23] UEHARA, K. eta MIZUNO, N. 2011. «Heterolytic dissociation of water demonstrated by crystal-to-crystal core interconversion from ( $\mu$-oxo)divana- 
Leticia Fernández-Navarro, Estibaliz Ruiz-Bilbao, Beñat Artetxe, Leire San Felices, Amaia Iturrospe, Santiago Reinoso

dium to bis( $\mu$-hydroxo)divanadium substituted polyoxometalates». Journal of American Chemical Society, 133, 1622-1625.

[24] FERNÁNDEZ DE LUIS, R., URTIAGA, M. K., MESA, J. L., ORIVE GÓMEZ DE SEGURA, J., ROJO, T. eta ARRIORTUA, M. I. 2011. $\ll\left\{\mathrm{Co}(\mathrm{HBpe})_{2}\right\}\left(\mathrm{V}_{4} \mathrm{O}_{12}\right)$ : pedal motion induced order-disorder $\mathrm{P} \overline{1} \rightarrow \mathrm{C} \overline{1}$ transition and disrupted $\mathrm{C} \overline{1} \rightarrow \mathrm{C} 2 / \mathrm{m}$ displacive transition due to thermal instability». CrystEngComm, 13, 6488-6498.

[25] REINOSO, S., ARTETXE, B. eta GUTIÉRREZ-ZORRILLA, J. M. 2018. «Single-crystal-to-single-crystal transformations triggered by dehydration in polyoxometalate-based compounds». Acta Crystallographica, C74, 12221242.

[26] ITURROSPE, A., ARTETXE, B., REINOSO, S., SAN FELICES, L., VITORIA, P., LEZAMA, L. eta GUTIÉRREZ-ZORRILLA, J. M. 2013. «Copper(II) complexes of tetradentade pyridyl ligands supported on Keggin polyoxometalates: single-crystal-to-single-crystal transformations promoted by reversible dehydration processes». Inorganic Chemistry, 52, 3084-3093.

[27] ITURROSPE, A., SAN FELICES, L., REINOSO, S., ARTETXE, B., LEZAMA, L. eta GUTIÉRREZ-ZORRILLA, J. M. 2014. «Reversible dehydration in polyoxometalate-based hybrid compounds: a study of single-crystal-to-single-crystal transformations in Keggin-type germanotungstates decorated with copper(II) complexes of tetradentate N-donor ligands». Crystal Growth \& Design, 14, 2318-2328.

[28] MARTÍN-CABALLERO, J., SAN JOSÉ WÉRY, A., ARTETXE, B., REINOSO, S., SAN FELICES, L., VILAS, J. L. eta GUTIÉRREZ-ZORRILLA, J. M. 2015. «Sequential single-crystal-to-single-crystal transformations promoted by gradual thermal dehydration in a porous metavanadate hybrid». CrystEngComm, 17, 8915-8925.

[29] MARTÍN-CABALLERO, J., SAN JOSÉ WÉRY, A., REINOSO, S., ARTETXE, B., SAN FELICES, L., EL BAKKALI, B., TRAUTWEIN, G., ALCAÑIZ-MONGE, J., VILAS, J. L. eta GUTIÉRREZ-ZORRILLA, J. M. 2016. «A robust open framework formed by decavanadate clusters and copper(II) complexes of macrocyclic polyamines: permanent microporosity and catalytic oxidation of cycloalkanes». Inorganic Chemistry, 55, 49704979.

[30] DISSEM, N., ARTETXE, B., SAN FELICES, L., LEZAMA, L; HADDAD, A. eta GUTIÉRREZ-ZORRILLA, J. M. 2018. «A Robust Framework Based on Polymeric Octamolybdate Anions and Copper(II) Complexes of Tetradentate N-donor Ligands». Crystals, $8,20$.

[31] MARTÍN-CABALLERO, J., ARTETXE, B., REINOSO, S., SAN FELICES, L., CASTILLO, O., BEOBIDE, G., VILAS, J. L. eta GUTIÉRREZZORRILLA, J. M. 2017. «Thermally-triggered crystal dynamics and permanent porosity in the first heptatungstate-metalorganic three-dimensional hybrid framework». Chemistry-A European Journal, 23, 14962-14974. 